Linguagem em (Dis)curso - LemD, v. 8, n. 1, p. 93-120, jan./abr. 2008

\title{
LULA E A METÁFORA DA CONQUISTA*
}

\author{
Tony Berber Sardinha*
}

\begin{abstract}
Resumo: $O$ objetivo deste trabalho é identificar e analisar as metáforas recorrentes nos discursos e pronunciamentos do presidente Luís Inácio Lula da Silva. O corpus utilizado na pesquisa é composto por 868 falas do presidente, compreendendo quase 1,8 milhão de palavras. Com o uso de ferramentas da Lingüística de Corpus e do arcabouço teórico da metáfora conceptual, notamos que a palavra 'conquista' se destacava entre as de potencial metafórico no corpus. A análise do uso dessa palavra mostrou que ela é altamente produtiva, gerando uma grande variedade de metáforas ao se combinar com um número alto de tópicos. Isso indica que a conquista é uma metáfora-chave no arsenal retórico do presidente, embora pouco notada. Além disso, o conjunto de metáforas relativas à conquista é coerente com a história de vida e a ideologia política do presidente, o que confere credibilidade ao seu discurso.
\end{abstract}

Palavras-chave: metáfora; Lingüística de Corpus; política; discurso.

\section{INTRODUÇÃO}

Luís Inácio Lula da Silva começou sua carreira de metalúrgico na região do $\mathrm{ABC}$ de São Paulo, como empregado do setor automotivo. Em 1975, tornou-se líder sindical da categoria dos metalúrgicos de São Bernardo do Campo e ajudou a fundar o PT, Partido dos Trabalhadores, em 1980. Disputou as eleições presidenciais de 1989, 1994 e 1998, obtendo sucesso em 2002 quando foi eleito presidente da República.

\footnotetext{
* Agradeço o apoio das seguintes agências: CNPq, processos 350455/2003-1, 307307/2006-9, 450239/2006-3; Capes, processo 0397/04-0; FAPESP, processo 06/00109-9. Também sou grato aos pareceristas que avaliaram o trabalho.

** Professor associado da Pontifícia Universidade Católica de São Paulo. Doutor em língua inglesa. E-mail: <tony@corpuslg.org>.
} 
Muitos consideram essa trajetória uma ascensão sem precedentes, na medida em que um operário chegou a chefe do Estado.

Uma das características mais notadas dessa ascensão é capacidade de retórica de Luís Inácio Lula da Silva. Tanto na porta da fábrica, enquanto líder metalúrgico, quanto em suas inúmeras aparições públicas e no papel de presidente da República, ele consegue cativar sua audiência como poucos. Mas tem sido durante seu mandato presidencial que um aspecto de seu discurso se tornou uma marca registrada: as metáforas.

O objetivo deste trabalho é identificar metáforas recorrentes nos discursos e pronunciamentos do presidente. A pesquisa partiu da necessidade de expor metáforas que passam despercebidas nas falas do presidente, mas que, devido à sua alta freqüência, podem influenciar seus ouvintes de maneira decisiva. Além disso, as metáforas recorrentes indicam como o presidente entende certos conceitos importantes da sua gestão. Antes de passar à investigação propriamente dita, será feita uma discussão acerca de como a mídia vê as metáforas do presidente e como elas podem ser interpretadas à luz da teoria da Metáfora Conceptual (LAKOFF; JOHNSON, 1980) e da Lingüística de Corpus (BERBER SARDINHA, 2004).

\section{METÁFORAS DE LULA NA MÍDIA}

Os jornais e revistas já notaram que o presidente Lula emprega metáforas para comunicar suas idéias. Uma das metáforas comentadas na mídia é a da churrascaria, em que o presidente compara a pressa de realizar as reformas políticas à pressa em saciar a fome:

Nós ainda temos muita coisa para fazer no Brasil. Muita. [...] Agora, de vez em quando, eu peço paciência, porque tem gente apressada. Eu não sei se vocês já perceberam, quando vocês vão numa churrascaria comer um rodízio, tem aquele apressado que tudo que é maionese que vem ele come, tudo que é lingüiça que vem ele come. Aí, quando chega a hora da coisa nobre, ele já está com o "bucho cheio", ele não quer mais a picanha, a costela, a chamada carne nobre. Ele já não consegue comer. Pagou por ela 
e não comeu, porque foi apressado. Então, temos que ter um certo controle na nossa ânsia, na nossa angústia de querer fazer as coisas com a rapidez que todo mundo necessita. Nós vamos fazer.

(Discurso no ato de lançamento do Pólo de Fruticultura da Amazônia, em Benevides, PA, 21 de agosto de 2003).

Uma outra metáfora que chamou a atenção da mídia foi a do esporte, que se manifestava pela expressão 'vestir a camisa', conforme ilustra a passagem abaixo:

Os governos, sozinhos, podem pouco. A integração sulamericana e o fortalecimento do Mercosul devem ser também objetivos dos empresários, dos trabalhadores e de toda a sociedade. Quero convidar as empresas a vestirem a camisa da integração. É preciso que nos unamos para buscar parceiros, integrar cadeias produtivas, fazer prospecção conjunta de mercados.

(Pronunciamento no Hotel Sheraton, Buenos Aires, Argentina, 16 de outubro de 2003)

Nesse exemplo, Lula compara integrar o Cone Sul economicamente com jogar em uma mesma equipe (de futebol, provavelmente).

Essas e outras metáforas foram amplamente divulgadas e comentadas na mídia. A razão pela qual foram tão notadas é sua saliência, isto é, a maneira como são deliberadamente destacadas do discurso; algumas são verdadeiras alegorias. No primeiro caso, o presidente conta uma história sobre um cliente apressado de uma churrascaria para fazer a ligação com seus críticos que cobram mais agilidade no governo. A saliência aqui é garantida de dois modos. Primeiro, pelo emprego da narrativa, que destoa do restante do discurso (uma argumentação), salientando assim a passagem metafórica. Segundo, pela evocação de um tópico marcante para muitos brasileiros: a fome. A narrativa desperta toda uma dramaticidade, ao colocar em cena um 
personagem que teria a oportunidade de 'se esbaldar', 'tirar a barriga da miséria', mas que não o faz por ter sido apressado. Com certeza, muitos se identificam com essa metáfora e, por conseguinte, com o argumento de que é preciso ter paciência para que as coisas certas aconteçam no momento certo.

No segundo caso, o presidente usa a necessidade de jogar em equipe para apregoar a integração de países da América do Sul. Essa metáfora do jogo em equipe tem um significado todo especial no contexto dos países envolvidos, que são tradicionais rivais no futebol. No esporte, uma seleção formada por jogadores brasileiros e argentinos seria muito forte; do mesmo modo, uma equipe formada pelas economias dos dois maiores países da América do Sul também seria muito competitiva.

Em ambos os casos, há uma moral da história bastante evidente. $\mathrm{Na}$ metáfora da churrascaria, trata-se de 'a pressa é inimiga da perfeição', e na do esporte, 'a união faz a força'. Parte do poder dessas metáforas reside justamente no fato de que elas aliam assuntos corriqueiros (churrascaria e futebol) a provérbios comuns.

Metáforas deliberadas como essas causam grande impacto mas são pouco comuns. Elas ocorrem em poucos discursos do presidente e, em geral, uma ou duas vezes apenas por discurso. Dessa forma, embora chamativas, elas não devem ser as únicas que o presidente emprega. Deve haver outras metáforas que são mais freqüentes e que, portanto, causem um impacto maior nos seus interlocutores, mesmo que seja de forma inconsciente. Para investigarmos tal possibilidade, precisamos de um aparato teórico que nos permita identificar metáforas convencionalizadas, isto é, que já fazem parte do uso comum da língua e que normalmente passam despercebidas na interação. $\mathrm{O}$ aparato teórico que usamos para essa investigação é a metáfora conceptual (LAKOFF; JOHNSON, 1980). Além disso, precisamos de um suporte teóricometodológico para verificar a extensão do uso metafórico nas centenas de discursos e pronunciamentos feitos pelo presidente, que no caso é fornecido pela Lingüística de Corpus (BERBER SARDINHA, 2004). Nas seções a seguir detalhamos esses dois aportes no contexto da presente investigação. 


\section{METÁFORA CONCEPTUAL}

"Uma metáfora conceptual ${ }^{1}$ é uma maneira convencional de conceitualizar um domínio de experiência em termos de outro, normalmente de modo inconsciente." 2 (LAKOFF, 2002, p. 4). Por exemplo, no caso da metáfora da churrascaria, temos GOVERNAR É SERVIR CHURRASCO EM UM RODÍZIO (Ou SER GOVERNADO É COMER CHURRASCO EM UM RODÍZIO) e no caso da metáfora do jogo em equipe, temos FAZER INTEGRAÇÃO ECONÔMICA É JOGAR EM CONJUNTO EM UMA MESMA EQUIPE. Uma metáfora conceptual é assim chamada porque expressa um conceito. No primeiro caso acima, a metáfora fornece um conceito de governo. Segundo esse conceito, governar seria servir churrasco em um rodízio. Esse é o conceito metafórico. No segundo caso, a metáfora fornece um conceito metafórico de integração econômica.

Essa teoria é de base cognitiva, pois propõe que as metáforas são construtos mentais, fundamentais para o entendimento da linguagem e para a vida em sociedade (BERBER SARDINHA, 2007). A principal obra sobre metáfora conceptual é 'Metaphors We Live By', de 1980 (LAKOFF; JOHNSON, 1980), cujo título em inglês significa algo como 'as metáforas que nos guiam'3. Ou seja, metaforicamente dizendo, somos guiados pelas metáforas que existem em nossa sociedade. Sem elas, não conseguiríamos interagir nem ser entendidos e nem mesmo fazer sentido da nossa cultura.

As metáforas conceptuais não são verbalizadas como tais. Ou seja, não dizemos 'governar é servir churrasco em rodízio', pois não seríamos entendidos, visto que essa expressão não é de uso corrente. Ela não foi licenciada pela metáfora conceptual. Tampouco dizemos integração econômica é um jogo em equipe' ou coisa parecida. As metáforas conceptuais são representações mentais dos conceitos e portanto

\footnotetext{
1 O termo em inglês 'conceptual' foi traduzido para o português por 'conceptual' e não por 'conceitual', em Zanotto et al., 2002, e tem se firmado como a tradução aceita pela comunidade. Empregaremos, portanto, a forma 'conceptual'. Por conceptual, entendemos uma metáfora que nos fornece um conceito de algo, em geral abstrato, como amor, tempo, discussão, etc.

2 'A conceptual metaphor is a conventional way of conceptualizing one domain of experience in terms of another, often unconsciously.'

3 A tradução brasileira da obra intitula-se 'Metáforas da vida cotidiana' (Zanotto et al., 2002).
} 
residem na mente dos indivíduos e são compartilhadas por pessoas de uma mesma cultura. As metáforas conceptuais circulam verbalmente por meio de metáforas lingüísticas ou expressões metafóricas, que são o correlato verbal das metáforas conceptuais. As metáforas lingüísticas referentes à metáfora conceptual do governo são 'estar com o bucho cheio', 'comer muita maionese', 'não esperar pela carne nobre', etc. Já no caso da metáfora da integração, temos 'vestir a camisa' e 'jogar unidos', entre outras.

Os conceitos representados pelas metáforas conceptuais são chamados de metafóricos porque unem dois domínios diversos. Um domínio é uma área de conhecimento ou de experiência humana. Nos exemplos acima, temos a união de 'governo' com 'churrascaria' por um lado, e de 'integração econômica' com 'jogo em equipe' de outro. Cada um desses pares de domínios não tem relação natural entre si: o conceito de governo é independente do de churrascaria, assim como o de integração econômica o é de praticar esporte. Nos nossos exemplos, governo é a ação de governar um país, enquanto churrascaria é um tipo de restaurante; formar um bloco econômico é uma ação governamental entre territórios geograficamente limitados (países), ao passo que praticar esporte coletivo é fazer atividade física em grupos divididos em equipes segundo regras previamente estabelecidas. Como essas entidades existem separadamente na sociedade, podemos nos referir a cada uma sem fazer alusão à outra. Prova disso é que uma enciclopédia apresenta entradas separadas para temas relativos a esses conceitos, como 'governo', 'restaurante', 'blocos econômicos' e 'esporte'.

Há dois tipos de domínio: fonte e alvo. O domínio-fonte é aquele a partir do qual conceitualizamos alguma coisa metaforicamente (em nossos exemplos, comer em rodízio de churrasco e praticar esportes coletivos). São algo concreto, advindo da experiência. Por outro lado, o domínio-alvo é aquele que desejamos conceitualizar; esse é o domínio abstrato; nos nossos exemplos, governo e integração econômica. Um mesmo domínio pode ser representado de forma mais geral ('atuação política' em vez de governo, ou 'atividade física' em vez de esporte) ou mais específica (respectivamente 'fazer reformas governamentais' e 'jogar na mesma equipe de futebol'), dependendo do contexto. Além disso, um mesmo domínio-fonte pode servir a várias metáforas conceptuais, ao unir-se a outros domínios-alvos; por exemplo, podemos evocar a espera 
pelas carnes do rodízio para nos referirmos a outras situações em que é preciso esperar por algo melhor que virá no final, como fazer poupança ou pagar aposentadoria; do mesmo modo, podemos nos referir a jogar em equipe para conceitualizar o trabalho numa empresa ou mesmo a vida em família.

As metáforas conceptuais fazem ligações entre esse domínios por meio de mapeamentos (mappings). No caso da churrascaria, temos os seguintes mapeamentos, entre outros: o restaurante é o país; o gerente da churrascaria é o chefe do governo (presidente); os garçons são os ministros, órgãos governamentais, etc.; os clientes do restaurante são o povo; a comida são as realizações do governo; a lingüiça ou maionese é uma ação governamental preparatória; a carne nobre é uma reforma estrutural; um cliente apressado ou desavisado é um crítico irresponsável do governo. No caso do jogo em equipe, temos, entre outros: a equipe é o bloco econômico; os jogadores da mesma equipe são os países do bloco; os jogadores da equipe adversária são os países de fora do bloco; a camisa da equipe é a cooperação entre os países do bloco; a partida é o comércio exterior; a bola são os valores ou produtos; o juiz é a Organização Mundial do Comércio.

Os desdobramentos (entailments) de uma metáfora conceptual são as inferências que podemos fazer a partir dos mapeamentos. No caso da churrascaria, podemos inferir que:

- Se governar mal é comer com pressa, governar bem é esperar a ordem de passagem dos espetos de carne de uma churrascaria.

- Se a ordem de passagem dos espetos normalmente implica em servir a melhor carne no final, um bom governo mostrará suas melhores realizações no final.

- Se a ordem de passagem dos espetos é definida pela gerência do estabelecimento, a ordem das realizações do governo é definida pelo presidente.

No caso do jogo em equipe:

- Se a partida é o comércio exterior, a vitória seria o superávit nas contas dos países do bloco econômico. Uma derrota, por outro lado, seria um déficit nas contas. 
- Se a equipe é o bloco econômico, o técnico da equipe deve ser um representante do governo de um dos países do bloco;

- Se os jogadores são os países, então deve haver jogadores de defesa e atacantes, isto é, que são mais e menos agressivos no comércio exterior.

Muitos desdobramentos são difíceis de resolver, tais como:

- Se SER GOVERNAdo É COMER CHURRASCO EM UM RODízIO, então o que é o estômago? Quem paga a conta? O que é a sobremesa?

- Se FAZER INTEGRAÇÃO ECONÔMICA É JOGAR EM CONJUNTO EM UMA MESMA EQUIPE, então o que é um gol? O que é uma prorrogação? Uma disputa de pênaltis?

\section{LINGÜÍSTICA DE CORPUS}

A Lingüística de Corpus se ocupa da coleta e análise de corpora, que são coletâneas de textos ou transcrições de fala armazenados em arquivo de computador (BERBER SARDINHA, 2004). Os corpora são coletados especificamente para serem alvo de pesquisa lingüística. Isso os diferencia de bibliotecas eletrônicas, que também são conjuntos de arquivos de computador, já que o propósito dessas não é permitir a análise lingüística, mas sim fornecer conteúdos diversos, como informação, cultura, entretenimento, etc.

Em geral, os corpora possuem milhões de palavras. O maior corpus de inglês de que se tem notícia é o Bank of English (Birmingham University, Grã-Bretanha), com cerca de meio bilhão de palavras. O maior corpus de português atual é o Banco de Português (PUCSP).

Devido à grande quantidade de dados que os corpora disponibilizam, torna-se indispensável a utilização de programas de computador na pesquisa em Lingüística de Corpus. Há vários tipos de programa para análise de corpus, como os listadores de freqüência (que contam o número de ocorrências de cada vocábulo), os concordanciadores (que exibem as várias ocorrências de uma dada 
palavra com trechos do texto) e os etiquetadores morfossintáticos (que identificam a classe gramatical de cada ocorrência de palavra do corpus). Esses programas trabalham de modo automático, podendo processar milhões de palavras dos arquivos do corpus sem a intervenção do pesquisador. Eles são empregados para garantir a exeqüibilidade e a confiabilidade da análise, e não para torná-la mais rápida ou fácil. Ou seja, os programas não são substitutos da análise manual; são a única opção viável frente aos dados.

O estudo da metáfora com corpora é relativamente recente; um dos primeiros trabalhos a respeito é Deignan (1999). Atualmente, vem aumentando o interesse em estudar metáforas em grandes coletâneas de dados, por duas razões. Em primeiro lugar porque os corpora estão ficando mais amplamente disponíveis e mais fáceis de coletar, dada a abundância de textos eletrônicos na Web e em outras fontes. Em segundo lugar porque uma das premissas básicas do estudo da metáfora na vertente conceptual é que a metáfora é um recurso corriqueiro e, portanto, freqüente. Isso traz à tona a necessidade do estudo da freqüência e dos usos típicos de metáforas. Os corpora proporcionam os dados necessários para o estudo da freqüência e da realização concreta no discurso.

Ao mesmo tempo em que a pesquisa em metáfora com corpora abre novas possibilidades, ela também impõe desafios. Um dos mais sérios é justamente o desenvolvimento de software compatível com a identificação de metáforas. Os programas de análise de corpora disponíveis não foram desenvolvidos para auxiliar o analista de metáfora, mas sim o pesquisador de Lingüística de Corpus que, em grande parte, se interessa pela freqüência e co-ocorrência de palavras e classes gramaticais. O analista de metáfora, por sua vez, precisa identificar significados metafóricos. Contudo, não há, ainda, tecnologias para fazer isso automaticamente em corpora. $\mathrm{O}$ resultado é que o analista de metáfora não pode solicitar a um software que encontre as ocorrências de metáfora em um corpus. Como se sabe, em Lingüística de Corpus 'inevitavelmente se começa pela palavra' (HOEY, 1997) e somente se encontra aquilo que se procura (DEIGNAN, 2005b). Tendo isso em mente, o que o analista normalmente faz é buscar certas palavras que, por alguma razão, devam possuir usos metafóricos, e ignorar as demais palavras do corpus. $\mathrm{O}$ analista seleciona algumas palavras, por sua vez, 
por meio de leituras de partes do corpus, por intuição ou por conhecimento prévio dos assuntos encontrados no corpus.

Entretanto, surgiu recentemente um programa de computador que faz busca por metáforas em corpora eletrônicos. Chamado de identificador de metáforas, o programa verifica cada palavra do corpus, comparando-a com bancos de dados de uso metafórico. Esses bancos de dados foram previamente construídos com base em análise manual de metáforas em corpus. O output do identificador é uma listagem com a probabilidade de uso metafórico das 3 mil palavras mais freqüentes do corpus. A partir dessa listagem, o analista pode escolher as palavras que mais lhe interessar para prosseguir com a pesquisa, verificando se foram usadas metaforicamente mesmo. Esse procedimento é mais racional do que escolher palavras com base em uma lista de freqüência, visto que esse tipo de lista não oferece informação sobre a probabilidade de uso metafórico, apenas a quantidade de ocorrências no corpus. $\mathrm{O}$ identificador está disponível na rede em http://www2.lael.pucsp.br/corpora.

\section{METODOLOGIA}

A metodologia da pesquisa relatada aqui, acerca das metáforas do presidente, foi implantada tendo em mente três pontos principais discutidos acima:

1) a necessidade de pesquisar metáfora em um corpus de pronunciamentos do presidente;

2) a necessidade de empregar um identificador de metáforas para auxiliar na detecção de candidatos a metáfora, isto é, as possíveis metáforas;

3) a necessidade de analisar qualitativamente cada ocorrência dos candidatos para verificar se realmente eram metáforas.

O corpus utilizado na pesquisa é composto por 868 pronunciamentos e discursos do presidente Luís Inácio Lula da Silva, retirados do sítio www.presidencia.gov.br em fevereiro de 2006, 
compreendendo a totalidade dos depoimentos disponíveis até então. O corpus possui 1.779.713 ocorrências ('tokens') e 32.757 formas ('types').

Os programas utilizados para análise do corpus foram:

- O identificador de metáforas disponível em http://www2.lael.pucsp.br/corpora. O programa fez uma triagem de todas as palavras do corpus e exibiu as 3 mil palavras com maior potencial metafórico.

- O concordanciador do WordSmith Tools (SCOTT, 1997), que serviu para verificar todas as ocorrências de uma determinada palavra.

Os procedimentos da pesquisa são detalhados a seguir.

\subsection{A triagem do identificador de metáforas}

Os textos do corpus foram submetidos ao identificador de metáforas, que forneceu uma listagem das 3 mil palavras com maior potencial de uso metafórico. A figura 1 a seguir mostra as 10 palavras no topo da listagem:

Sorted by probability

Fri Sep 1 08:08:54 BRT 2006

\begin{tabular}{|c|c|c|c|c|c|c|c|}
\hline \# & Word & $\operatorname{Tag}$ (Prob) & Vehicle & Left Bndl & Right Bndl & Framewk & Wordclass \\
\hline 000001 & conquistar & .9250 & 1.0000 & 1.0000 & 1.0000 & .9210 & .7041 \\
\hline 000002 & dar & .9166 & .9583 & 1.0000 & 1.0000 & .9210 & .7041 \\
\hline 000003 & niveis & .9068 & 1.0000 & 1.0000 & 1.0000 & .8085 & .7259 \\
\hline 000004 & crescer & .9033 & .9625 & 1.0000 & 1.0000 & .8500 & .7041 \\
\hline 000005 & segmentos & .9024 & 1.0000 & 1.0000 & 1.0000 & .8235 & .6887 \\
\hline 000006 & fazer & .9022 & .8863 & 1.0000 & 1.0000 & .9210 & .7041 \\
\hline 000007 & passar & .9011 & .8807 & 1.0000 & 1.0000 & .9210 & .7041 \\
\hline 000008 & passou & .8981 & .9531 & 1.0000 & 1.0000 & .8333 & .7041 \\
\hline 000009 & caminho & .8980 & .8593 & 1.0000 & 1.0000 & .9423 & .6887 \\
\hline 000010 & longo & .8925 & .9513 & 1.0000 & 1.0000 & .7857 & .7259 \\
\hline
\end{tabular}

Figura 1 - Amostra da listagem do identificador de metáforas.

A lista contém as seguintes colunas:

- \#: número seqüencial.

- Word: palavra do corpus.

- Tag(Prob): etiqueta indicando a probabilidade de uso metafórico. É a média aritmética das probabilidades individuais 
abaixo. A probabilidade vai de 0 a 1 . Isso pode ser traduzido em porcentagens multiplicando-se por 100. Assim, .5 (isto é, 0,5) significa $50 \%$ de probabilidade de uso metafórico, pois $100 \times 0,5$ $=50$.

- Vehicle: probabilidade de uso metafórico segundo o banco de dados de Veículos, que são palavras previamente identificadas, em uma análise de corpus, como tendo sido usadas metaforicamente.

- Left Bndl: probabilidade de uso metafórico segundo o banco de dados de pacotes lexicais à esquerda da palavra. Pacotes lexicais (lexical bundles) são seqüências fixas de palavras (BIBER; CONRAD, 1999), de extensão variada. O banco de dados de pacotes lexicais à esquerda guarda os pacotes lexicais de três palavras, previamente identificados em uma análise de corpus, que ocorreram imediatamente à esquerda de uma palavra usada metaforicamente.

- Right Bndl: probabilidade de uso metafórico segundo o banco de dados de pacotes lexicais à direita da palavra. Similar ao anterior, com exceção de que os pacotes ocorreram imediatamente à direita de uma palavra usada metaforicamente.

- Frame: probabilidade de uso metafórico segundo o banco de dados de enquadramentos colocacionais. Um enquadramento colocacional é uma seqüência do tipo 'a _ _ da', em que o elemento central ('__') é variável, podendo representar 'a questão da', 'a casa da', 'a visão da', etc. Esse banco de dados registra os enquadramentos, previamente encontrados numa análise de corpus, que compreendiam palavras de uso metafórico.

- Wordclass: probabilidade de uso metafórico segundo o banco de dados de classes gramaticais. Esse banco registra a probabilidade de uso metafórico das classes gramaticais (substantivo, verbo, adjetivo, advérbio, pronome, conjunção, preposição, artigo e numeral) como uma média de todas as palavras com uso metafórico identificadas em uma pesquisa prévia com corpus. 
A palavra no topo da lista é 'conquistar', com 92,5\% de probabilidade de uso metafórico. A partir dela foram buscadas, na etapa seguinte, todas as ocorrências de 'conquista*', isto é, 'conquistar', 'conquistarei', 'conquistaremos', 'conquista', etc.

\subsection{A determinação dos usos metafóricos}

Esta etapa se refere à análise qualitativa dos dados, em que cada ocorrência das palavras selecionadas foi levantada, em seu contexto, e julgada em termos de seu uso metafórico. Para tanto, foi feita uma concordância, com o programa Concord do WordSmith Tools, de 'conquista*', conforme explicado acima. A concordância resultou em 619 ocorrências.

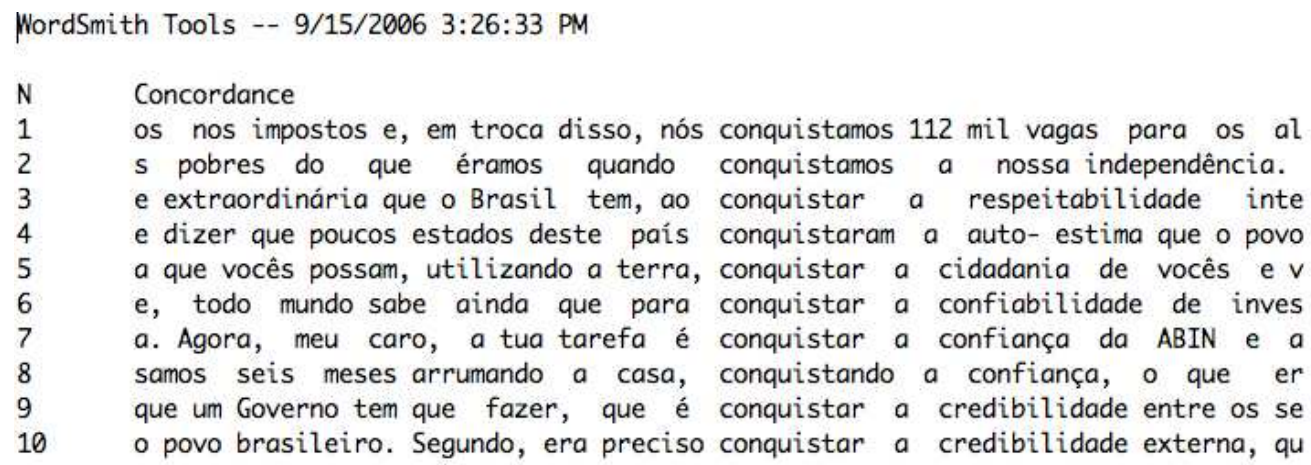

Figura 2 - Amostra da concordância de 'conquista*' produzida com o WordSmith Tools.

Havia nos dados dois usos literais de 'conquista', referentes à cidade de Vitória da Conquista. Esses foram pegos pela concordância porque não foi feita a distinção entre maiúsculas e minúsculas na busca, já que havia a possibilidade de um uso legítimo de metáfora ter sido grafado com pelo menos uma letra maiúscula. Esses casos literais foram eliminados da análise.

Desse modo, havia 617 ocorrências de metáfora entre as 619 ocorrências de 'conquista*'. Isso dá uma porcentagem de uso da metáfora de $99,7 \%$, maior ainda do que o previsto pelo identificador $(92,5 \%)$. De qualquer modo, o etiquetador acertou ao apontar uma palavra com altíssimo uso metafórico no corpus. 
106

Caso o identificador não tivesse sido usado, talvez 'conquista*' não tivesse sido descoberta entre as demais palavras, pois essas palavras não são especialmente freqüentes no corpus. Elas começam a surgir na lista de freqüência de palavras do corpus a partir da posição 1062, conforme mostra a tabela a seguir.

\begin{tabular}{l|l|r}
\hline $\begin{array}{l}\text { Posição na lista } \\
\text { de Freqüência }\end{array}$ & Palavra & Freqüência \\
\hline 1062 & conquista & 178 \\
\hline 1228 & conquistar & 150 \\
\hline 1896 & conquistas & 87 \\
\hline 2948 & conquistaram & 48 \\
\hline 3001 & conquistamos & 47 \\
\hline 3572 & conquistado & 35 \\
\hline 4281 & conquistando & 27 \\
\hline 8032 & conquistada & 10 \\
\hline 8535 & conquistados & 9 \\
\hline 10828 & conquistaremos & 6 \\
\hline 10829 & conquistadas & 6 \\
\hline 12025 & conquistarem & 5 \\
\hline 16031 & conquistarão & 3 \\
\hline 16032 & conquistam & 3 \\
\hline 20243 & conquistassem & 2 \\
\hline 30167 & conquistava & 1 \\
\hline 30168 & conquistasse & 1 \\
\hline 30169 & conquistarmos & 1 \\
\hline Total & & 619 \\
\hline
\end{tabular}

Tabela 1 - Palavras capturadas pelo concordanciador e suas posições na lista de freqüência do corpus.

As palavras de conteúdo mais freqüentes no corpus são 'brasil', 'gente' e 'país', nas posições 22, 26 e 27, respectivamente, da lista (vide anexo). No identificador, elas aparecem, respectivamente, nas posições 63, 974 e 177. Daí, pode-se tirar duas conclusões: 
1) Palavras de alto uso metafórico, e que, portanto, têm um papel importante no discurso, não são necessariamente as de maior freqüência;

2) É realmente necessária uma ferramenta que leve isso em conta e identifique as palavras com principal potencial metafórico sem se influenciar pela freqüência no corpus.

Um problema com a análise de metáforas em concordâncias é a quantidade de texto que se necessita ler para determinar se um uso é metafórico ou não. A extensão default de cada linha da concordância do WordSmith Tools é 80 caracteres. Durante a análise, foi verificado que em alguns casos essa quantidade de contexto não era suficiente para determinar o uso metafórico de uma palavra. Por isso, ele foi expandido para 380 caracteres e posteriormente para o texto completo. Conforme mostra a tabela a seguir, na grande maioria dos casos $(82 \%) 80$ caracteres foram suficientes para determinar se havia uso metafórico. Nos restantes $18 \%$ foi preciso um contexto maior, sendo que em 13,5\% dos casos bastou aumentá-lo para 380 caracteres e em apenas 4,5\% dos casos foi preciso ler o texto completo.

\begin{tabular}{l|r|r}
\hline Contexto & Casos & $\%$ \\
\hline 80 caracteres & 506 & $82.17 \%$ \\
\hline 380 caracteres & 83 & $13.45 \%$ \\
\hline Texto completo & 28 & $4.54 \%$ \\
\hline
\end{tabular}

Tabela 2 - Contexto necessário para determinar uso metafórico.

Esses dados indicam que o uso metafórico é marcado localmente, na proximidade do uso da palavra. O falante emprega padrões de uso que deixam claro ao ouvinte que se trata de uma metáfora lingüística. Isso já havia sido apontado por Deignan (2005a), que notou que as colocações que exprimem um uso metafórico são diferentes daquelas que exprimem um uso literal. Há, portanto, pouco espaço para ambigüidade.

A palavra 'conquistar' e suas derivações estão ligadas ao domíniofonte da GUERRA ou das BATALHAS. Concretamente, elas representam uma vitória em um conflito braçal ou armado. Sendo assim, na postulação das metáforas conceptuais que subjazem às metáforas 


\section{8}

lingüísticas identificadas na concordância, foi utilizada a matriz A OBTENÇÃO DE ALGO É RESULTADO DE UMA BATALHA VITORIOSA, em que ALGO é substituído, na formulação específica, pelo domínio-alvo da metáfora. O domínio-alvo varia de acordo com aquilo que está sendo metaforizado em cada instância e precisou ser determinado com a análise das concordâncias, por meio do que chamamos de identificação do objeto da conquista.

Por objeto da conquista, entendemos aquilo que foi conquistado. Formalmente, o objeto da conquista faz parte do Tópico da metáfora. Tópico e Veículo são os dois componentes que formam uma metáfora lingüística (CAMERON, 2003). O Veículo compreende as palavras usadas metaforicamente. O Tópico, por sua vez, compreende as palavras não empregadas metaforicamente. Por exemplo, na citação a seguir o Veículo é 'terá conquistado' e o Tópico é 'a nossa juventude' e 'definitivamente, a alegria' ${ }^{4}$. Nesse caso, anotamos 'juventude' como o objeto da conquista.

Daqui a alguns anos, a nossa juventude terá conquistado, definitivamente, a alegria.

No exemplo a seguir, o Veículo é ‘conquistamos’ e o Tópico, 'aliados internacionais':

Conquistamos aliados internacionais.

Nesse caso, anotamos 'aliados' como o objeto da conquista.

Depois de anotar o objeto da conquista em cada linha da concordância, foi feita a contagem dos objetos mais freqüentemente evocados e a postulação das metáforas conceptuais subjacentes aos usos metafóricos.

\section{AS METÁFORAS CONCEPTUAIS DE CONQUISTA}

Os resultados apresentados acima indicam que o presidente Lula tem como marca de seu discurso o uso metafórico da palavra 'conquista'

\footnotetext{
4 'Daqui a alguns anos' forma outra metáfora lingüística, por isso não foi incluída como Tópico da metáfora em questão.
}

BERBER-SARDINHA - Lula e a metáfora... 
e de suas derivações. Nesta seção apresentaremos as metáforas conceptuais que subjazem às metáforas lingüísticas encontradas e as licenciam.

Como dissemos acima, a postulação das metáforas conceptuais dependeu da identificação dos objetos de 'conquista*' em cada linha da concordância.

Foram identificados 163 diferentes objetos da conquista, o que dá uma média de 3,8 usos por objeto. Isso indica que o presidente utiliza conquista para se referir a uma grande quantidade de Tópicos, o que reforça a centralidade da conquista no seu discurso.

Contudo, a freqüência de uso dos objetos é bastante desigual - o presidente reutiliza muito alguns objetos e emprega raramente muitos outros. Dezoito tópicos (11\% dos 163) respondem por dois terços de todos os usos (isto é, 409 das 617 ocorrências). Esses dezoito objetos da conquista mais freqüentes são apresentados na Tabela 3.

\begin{tabular}{l|r|r|r}
\hline Objeto & Frequência & $\%$ & $\%$ acumulada \\
\hline$<$ geral $>$ & 160 & $25.93 \%$ & $25.93 \%$ \\
\hline cidadania & 61 & $9.89 \%$ & $35.82 \%$ \\
\hline espaço & 32 & $5.19 \%$ & $41.00 \%$ \\
\hline direito & 29 & $4.70 \%$ & $45.71 \%$ \\
\hline independência & 20 & $3.24 \%$ & $48.95 \%$ \\
\hline credibilidade & 20 & $3.24 \%$ & $52.19 \%$ \\
\hline mercado & 11 & $1.78 \%$ & $53.97 \%$ \\
\hline avanços & 10 & $1.62 \%$ & $55.59 \%$ \\
\hline medalha & 9 & $1.46 \%$ & $57.05 \%$ \\
\hline desenvolvimento & 8 & $1.30 \%$ & $58.35 \%$ \\
\hline democracia & 8 & $1.30 \%$ & $59.64 \%$ \\
\hline respeito & 7 & $1.13 \%$ & $60.78 \%$ \\
\hline liberdade & 7 & $1.13 \%$ & $61.91 \%$ \\
\hline confiança & 7 & $1.13 \%$ & $63.05 \%$ \\
\hline oportunidade & 6 & $0.97 \%$ & $64.02 \%$ \\
\hline paz & 5 & $0.81 \%$ & $64.83 \%$ \\
\hline andar de cabeça erguida & 5 & $0.81 \%$ & $65.64 \%$ \\
\hline vitória & 4 & $0.65 \%$ & $66.29 \%$ \\
\hline
\end{tabular}

Tabela 3 - Freqüência dos principais objetos de 'conquista*'. 
O objeto mais freqüente é um objeto geral, indefinido, sinalizado pelo código '<geral >' na tabela, o que ocorre em mais de um quarto dos casos. Nessas instâncias, o presidente fala de conquistas de modo amplo, sem especificar claramente de que elas consistem. Normalmente, essas conquistas gerais são expressas pelos colocados 'coisa/s', 'aquilo', 'as' e 'muitas', conforme ilustra a concordância a seguir.

94 nós ficarmos chorando aquilo que não conquistamos, ainda, e não agradecer a D
95 numa pessoa forte, sadia e, quem sabe, conquistar alguma coisa na vida. E eu a
96 sse unido, para que nós pudéssemos conquistar algumas coisas. Em pouco
99 , mas ficar pensando no que a gente vai conquistar amanhã, no dia seguinte, ou
100 er as coisas boas que nós mesmos conquistamos, ao invés de comemorar a
105 sforço nacional quem atribui as atuais conquistas apenas e tão somente a uma co
107 m sabem que cada migalha que vocês conquistaram aqui dentro foi às custas
109 terra do Sul da Bahia conseguiram conquistar aquilo que é mais sagrado no
110 is organizados, vão ter muito mais conquistas. As cooperativas estarão
111 nunca e eu tenho certeza que vou conquistar as coisas em que eu acredito
112 e julga mais rapidamente, então a gente conquista as coisas.
118 m, junto conosco, construído o que nós conquistamos até agora.
133 ro trabalhar com números menores e conquistar coisas maiores do que colocar
134 s também vieram com muita vontade de conquistar coisas. E também conseguimos
136 conta de aue as coisas não podem ser conquistadas com a facilidade aue muitas Figura 3 - Concordância de 'conquista*' referente ao objeto '<geral>'.

Como essas conquistas se referem a melhorias de um modo geral na vida das pessoas, podemos dizer que a metáfora conceptual subjacente seria talvez A OBTENÇÃO DE MELHORIAS EM GERAL É RESULTADO DE UMA BATALHA VITORIOSA.

O segundo objeto mais comum é 'cidadania', com cerca de 10\% das ocorrências. A concordância abaixo ilustra esses usos:

5 a que vocês possam, utilizando a terra, conquistar a cidadania de vocês e v 16 o. Por conta dessa profissão eu pude conquistar a minha cidadania, trabal 23 orque é através do emprego que a pessoa conquista a sua cidadania plena, sust 24 de dar oportunidade às pessoas para conquistarem a sua cidadania. Até po 26 , ainda tenha famílias que não tenham conquistado a sua plena cidadania, $g$ 27 o, onde o povo possa, definitivamente, conquistar a sua cidadania e conquista 28 das crianças aos mais idosos, possam conquistar a sua cidadania real.

29 restante da terra, podendo ela, também, conquistar a sua cidadania, e não ficar 32 parentes seus aqui dentro e, por isso, conquistaram a cidadania de ter um e 33 êm posses, em que as pessoas que já conquistaram a cidadania não tenham $m$ Figura 4 - Concordância de 'conquista*' referente ao objeto 'cidadania'. 
As metáforas lingüísticas de conquista da cidadania são geralmente realizadas de modo formulaico, com o padrão 'conquistar a (sua) cidadania'; algumas vezes aparece 'plena', 'de modo pleno' ou 'real' para enfatizar o uso.

A metáfora conceptual subjacente parece ser A OBTENÇÃO DA CIDADANIA É RESULTADO DE UMA BATALHA VITORIOSA. Esse é um caso interessante, pois cidadania é uma noção bastante ampla. Segundo o dicionário Houaiss online (http://houaiss.uol.com.br/), cidadania significa 'condição de pessoa que, como membro de um Estado, se acha no gozo de direitos que lhe permitem participar da vida política'. Claramente, essa definição entra em contradição com os usos feitos pelo presidente por meio de sua metáfora, visto que para ele a cidadania é uma conquista (isto é, algo por que se deva lutar), enquanto que para o dicionário é uma condição (isto é, algo que já se possui). Ou seja, são dois pontos de vista diferentes. O presidente enfatiza o processo de chegar à cidadania (com a metáfora da conquista), enquanto o dicionário realça o estado de alguém que já a possua.

O terceiro objeto mais freqüente é 'espaço', com cerca de 5\% das ocorrências. A concordância abaixo ilustra esse uso.

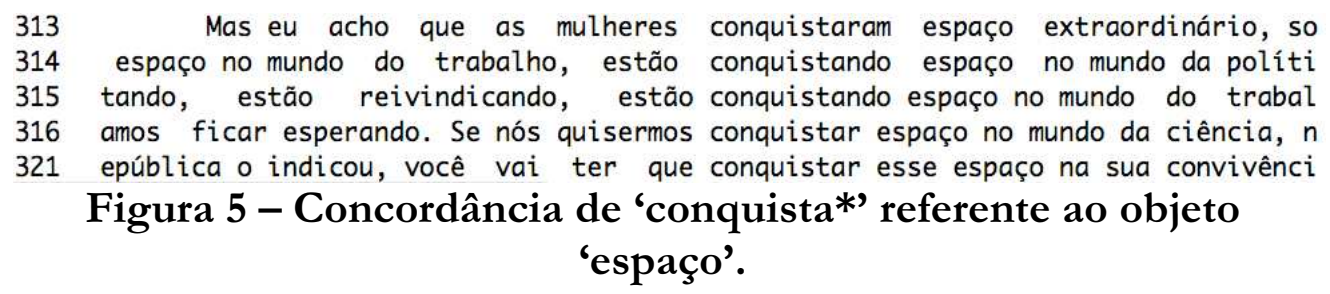

'Espaço' é usado com um sentido impreciso, que o dicionário Houaiss online define de modo amplo como 'oportunidade'. Na verdade, trata-se de um uso metafórico, advindo da metáfora conceptual A VIDA É UM RECEPTÁCULO. Essa mesma metáfora é responsável por expressões do tipo 'conseguir um lugar para si, 'ocupar um lugar de destaque', 'ganhar um lugar de honra', etc. Assim, podemos interpretar 'espaço' como significando oportunidade, chance, destaque, etc., o que podemos parafrasear como 'chances de melhoria na vida' ou simplesmente 


\section{2}

'melhoria de vida'. A metáfora conceptual seria, então, A OBTENÇÃO DE MELHORIA DE VIDA É RESULTADO DE UMA BATALHA VITORIOSA.

O próximo objeto é 'avanços', que expressa uma metáfora conceptual diferente: PROGRESSO É UM CAMINHO PARA A FRENTE. Assim, temos dois veículos da mesma metáfora lingüística que estão licenciados por metáforas conceptuais diferentes. Isso propicia a seguinte leitura:

\begin{tabular}{l|l|l}
\hline Veículo & Domínio-alvo & Domínio-fonte \\
\hline avanço & PROGRESSO & UM CAMINHO PARA A FRENTE \\
\hline conquista & OBTENÇÃO DE & RESULTADO DE UMA BATALHA \\
& MELHORIAS & VITORIOSA \\
\hline
\end{tabular}

Tabela 4 - Domínios de 'avanço' e 'conquista'.

A tabela mostra as duas metáforas conceptuais imediatas de cada Veículo. Porém, devido à junção das duas metáforas, temos duas metáforas conceptuais extras, resultantes do 'cruzamento' entre o domínio-alvo de uma com o domínio-fonte de outra: PROGRESSO É RESULTADO DE UMA BATALHA VITORIOSA e OBTENÇÃO DE MELHORIAS É UM CAMINHO PARA A FRENTE. Essas metáforas 'cruzadas' fazem sentido: progresso, sendo uma melhoria, é passível de ser metaforizado como resultado de uma batalha vitoriosa, e a obtenção de melhorias pode ser metaforizada como o percurso de um caminho à frente. Essa junção parece ter o efeito de reforçar mutuamente as metáforas imediatas, de PROGRESSO COMO CAMINHO À FRENTE e de MELHORIAS COMO RESULTADO DE BATALHA.

Um outro caso em que há reforço da metáfora da conquista pelo emprego de outra metáfora é 'andar de cabeça erguida', que evoca a metáfora orientacional PARA CIMA É MELHOR. A tabela 5 traz a decomposição das metáforas envolvidas.

Como no caso anterior, as duas metáforas imediatas (expressas na tabela) se cruzam, resultando em duas novas metáforas conceptuais: TER AUTO-ESTIMA É RESULTADO DE UMA BATALHA VITORIOSA e OBTENÇÃO DE MELHORIAS É PARA CIMA. Essas duas metáforas são perfeitamente possíveis, já que (1) a obtenção da auto-estima pode ser um processo longo e árduo de auto-conhecimento (e portanto passível 
de ser metaforizado como uma batalha) e (2) conseguir melhorias na vida é algo positivo e gratificante (e portanto para cima). O efeito dessa combinação metafórica parece também ser o de reforço, no sentido de que uma metáfora soma-se à outra.

\begin{tabular}{l|l|l}
\hline Veículo & Domínio alvo & Domínio fonte \\
\hline $\begin{array}{l}\text { andar de cabeça } \\
\text { erguida }\end{array}$ & TER AUTO-ESTIMA & PARA CIMA \\
\hline conquista & OBTENÇÃO DE & $\begin{array}{l}\text { RESULTADO DE UMA } \\
\text { BATALHA VITORIOSA }\end{array}$ \\
\hline
\end{tabular}

Tabela 5 - Domínios de 'andar de cabeça erguida' e 'conquista'.

O objeto 'vitória' é um caso interessante, pois vitórias são literalmente conquistas de batalhas. Visto desse modo, não se trata de uma metáfora. Porém, se desmetaforizarmos o objeto, reescrevendo-o como 'melhoria de vida', chegamos à metáfora conceptual A OBTENÇÃO DE MELHORIAS NA VIDA É RESULTADO DE UMA BATALHA VITORIOSA, que foi discutida nos dois exemplos anteriores.

Por restrições de espaço, as demais metáforas aparecem sumarizadas na Tabela 6. Nota-se que a única a fugir da matriz A OBTENÇÃO DE ALGO É RESULTADO DE UMA BATALHA VITORIOSA é ESPORTE É GUERRA, relativa ao objeto 'medalha'. Medalhas são prêmios concretos em eventos esportivos; assim, o que é metaforizado é o próprio esporte. Desse modo, fica licenciada de modo lógico a metáfora lingüística 'conquista de medalha', pois: se esporte é uma guerra, e medalha é conquista de um esporte, então medalha é conquista de guerra.

As metáforas da conquista registradas aqui indicam que esse conjunto de metáforas é um elemento essencial para o discurso do presidente. Elas são compatíveis com a história de vida do presidente: como ele mesmo diz, é uma pessoa que lutou muito na vida:

E eu, hoje, Presidente da República, não tenho vergonha de dizer para vocês: eu vinha a pé, lá da Igreja Nossa Senhora Aparecida até a Rua 2, lá na Ponte Preta, porque não tinha 30 centavos para pagar o ônibus. E não era uma vez, não, foram muitas vezes. Eu estou dizendo isso porque eu sou o exemplo de que ninguém 


\section{4}

deve desanimar por situação adversa. Ninguém pode baixar a cabeça. Se eu tivesse baixado a cabeça, possivelmente eu fosse um derrotado. Eu levantei a cabeça, lutei e hoje estou aqui, Presidente da República, numa demonstração que qualquer um de vocês, se acreditar no sonho de vocês, tiverem determinação, amanhã vocês poderão chegar onde eu cheguei, ou chegar muito mais do que eu cheguei. (Discurso por ocasião da visita ao Ponto de Cultura da Comunidade de Heliópolis, São Paulo, SP, 3 de outubro de 2005).

\begin{tabular}{|c|c|}
\hline Objeto & Metáfora Conceptual \\
\hline direitos & $\begin{array}{l}\text { A OBTENÇÃO DE DIREITOS LEGAIS É } \\
\text { RESULTADO DE UMA BATALHA VITORIOSA }\end{array}$ \\
\hline independência & $\begin{array}{l}\text { A OBTENÇÃO DE INDEPENDÊNCIA É } \\
\text { RESULTADO DE UMA BATALHA VITORIOSA }\end{array}$ \\
\hline credibilidade & $\begin{array}{l}\text { A OBTENÇÃO DE CREDIBILIDADE É } \\
\text { RESULTADO DE UMA BATALHA VITORIOSA }\end{array}$ \\
\hline $\begin{array}{l}\text { mercados } \\
\text { consumidores dos } \\
\text { produtos brasileiros }\end{array}$ & $\begin{array}{l}\text { A OBTENÇÃO DE MERCADOS PARA } \\
\text { EXPORTAÇÃO É RESULTADO DE UMA } \\
\text { BATALHA VITORIOSA }\end{array}$ \\
\hline medalha & ESPORTE É GUERRA \\
\hline desenvolvimento & $\begin{array}{l}\text { A OBTENÇÃO DE DESENVOLVIMENTO } \\
\text { ECONÔMICO OU SOCIAL É RESULTADO DE } \\
\text { UMA BATALHA VITORIOSA }\end{array}$ \\
\hline democracia & $\begin{array}{l}\text { A OBTENÇÃO DA DEMOCRACIA É } \\
\text { RESULTADO DE UMA BATALHA VITORIOSA }\end{array}$ \\
\hline respeito & $\begin{array}{l}\text { A OBTENÇÃO DE RESPEITO PARA CONSIGO } \\
\text { É RESULTADO DE UMA BATALHA } \\
\text { VITORIOSA } \\
\end{array}$ \\
\hline liberdade & $\begin{array}{lccc}\text { A } & \text { OBTENÇÃO DA } & \text { LIBERDADE } & \text { É } \\
\text { RESULTADO DE UMA BATALHA VITORIOSA }\end{array}$ \\
\hline confiança & $\begin{array}{l}\text { A OBTENÇÃO DA CONFIANÇA É } \\
\text { RESULTADO DE UMA BATALHA VITORIOSA }\end{array}$ \\
\hline oportunidade & $\begin{array}{l}\text { A OBTENÇÃO DE OPORTUNIDADES É } \\
\text { RESULTADO DE UMA BATALHA VITORIOSA }\end{array}$ \\
\hline paz & $\begin{array}{l}\text { A OBTENÇÃO DA PAZ É RESULTADO DE } \\
\text { UMA BATALHA VITORIOSA }\end{array}$ \\
\hline
\end{tabular}

Tabela 6 - Objetos e metáforas conceptuais restantes.

BERBER-SARDINHA - Lula e a metáfora... 
Além disso, a metáfora da conquista é coerente com sua ideologia política marxista, de luta de classes. Segundo essa visão, os direitos da classe trabalhadora precisam ser conquistados no enfrentamento com as classes dirigentes, opressoras. Assim, ao evocar as metáforas da conquista, Lula faz ressoar a ideologia marxista, que é coerente com a posição política original de seu partido (PT).

Essa coerência das metáforas com a história pessoal e política do orador é muito importante, pois lhe confere credibilidade. Dificilmente um orador que viesse de uma classe abastada poderia evocar a metáfora da conquista com o mesmo grau de sucesso.

\section{CONCLUSÃO}

Luís Inácio Lula da Silva é um orador de sucesso. Sabe empregar como poucos uma retórica que fala de perto ao povo mais simples do país, combinando com eficiência linguagem verbal e corporal para criar uma imagem de uma pessoa que sofreu muito na vida, mas que soube lutar e vencer as dificuldades até chegar ao cargo mais importante do país. Com certeza, um ingrediente fundamental de seu desempenho retórico é o uso de metáforas. A imprensa tem destacado algumas metáforas que sobressaem no seu discurso, como a do churrasco ou a do futebol. Nosso ponto de partida foi justamente que, como orador experiente e eficiente que é, não pode depender apenas dessas metáforas deliberadas; pensamos que deve haver outras metáforas em grande variedade e quantidade que, embora (quase) imperceptíveis, têm um papel tão ou mais importante do que as metáforas mais óbvias.

A triagem apresentada aqui mostrou que há um grande número de metáforas em potencial, dentre as quais selecionamos 'conquista' para uma análise detalhada. Mostramos que 'conquista' é altamente produtiva, gerando uma grande variedade de metáforas ao se combinar com um número alto de tópicos. Isso demonstra que a metáfora da conquista é um elemento chave no arsenal retórico do presidente, embora seja pouco (ou nada) notada. A análise também revelou o emprego de metáforas como elemento de reforço de outras metáforas. Além disso, o conjunto 


\section{6}

de metáforas relativas à conquista é coerente com a história de vida e a ideologia política do presidente, o que confere credibilidade ao seu discurso.

No fundo, a conquista é uma verdadeira metáfora da vida de Luís Inácio Lula da Silva. Uma pessoa que nasceu muito pobre, no interior do país, migrou para a cidade grande, trabalhou, 'lutou e venceu', sendo hoje presidente reeleito do país. Trata-se do verdadeiro sonho de ascensão de classe: o operário que chegou a presidente, assim como Lech Walesa, antes dele.

Essa metáfora é tão significativa que ainda vale para sua vida presente, como demonstrou a campanha para a reeleição. Segundo Da Matta (2006, p. D12):

[...] a imagem do candidato Lula, com sua farta cabeleira e barba e, melhor que tudo isso, seu suor que - entre nós - sinaliza o trabalho duro, o esforço e, mais do que a emoção, a vibração de quem - apesar de ser presidente - está na luta querendo vencer.

Esperamos que este trabalho venha a mostrar caminhos para o estudo da metáfora no discurso do presidente Luís Inácio Lula da Silva que ultrapassem aqueles exemplos mais óbvios, a fim de que possamos entender um pouco melhor a razão de seu sucesso como orador.

\section{REFERÊNCIAS}

BERBER SARDINHA, T. Lingüística de corpus. São Paulo: Manole, 2004. $410 \mathrm{p}$.

Metáfora. São Paulo: Parábola, 2007. 168 p.

BIBER, D.; CONRAD, S. Lexical bundles in conversation and academic prose. In: HASSELGARD, H.; OKSEFJELL, S. (Eds.). Out of corpora: studies in honour of Stig Johansson. Amsterdam; Atlanta: Rodopi, 1999. p. 181-190.

CAMERON, L. Metaphor in educational discourse. London: Continuum, 2003. 294 p. 
DA MATTA, R. Renovar ou repetir. O Estado de S.Paulo, 1 de Nov., D12. 2006.

DEIGNAN, A. Corpus-based research into metaphor. In: CAMERON, L; LOW, G. (Eds.). Researching and applying metaphor. Cambridge: Cambridge University Press, 1999. p.177-199.

Metaphor and corpus linguistics. Amsterdam; Philadelphia: John Benjamins, 2005a. 235 p.

Researching Metaphor in Electronic Corpora - Round Table. CONFERENCE ON METAPHOR IN LANGUAGE AND THOUGHT, 2. Niterói, RJ, 2005b.

HOEY, M. From concordance to text structure: new uses for computer corpora. In: LEWANDOSWKA-TOMASZCZYK, B.; MELIA, P. J. (Eds.). PALC'97: practical applications in language corpora. Lodz: Lodz University Press, 1997. p.2-22.

LAKOFF, G. Moral politics: how liberals and conservatives think. 2nd ed. Chicago: University of Chicago Press, 2002.

LAKOFF, G.; JOHNSON, M. Metaphors we live by. Chicago: University of Chicago Press, 1980. 242 p.

SCOTT, M. WordSmith tools. 3rd version. Oxford: Oxford University Press, 1997. [programa para computador]

ZANOTTO, M. S.; MOURA, H. M. M.; NARDI, M. I. A.; VEREZA, S. C.. Apresentação. In: LAKOFF, G.; JOHNSON, M. Metáforas da vida cotidiana. Campinas: Mercado de Letras, 2002. p. 1-20. 


\section{8}

\section{ANEXO}

\section{As 50 palavras mais freqüentes do corpus.}

Palavra

1 que

2 de

$3 \quad \mathrm{a}$

$4 \quad e$

50

6 do

7 para

$8 \mathrm{da}$

9 กต๊๋

10 é

$11 \mathrm{um}$

12 ell

$13 \mathrm{com}$

14 en

15 nós

16 uma

17 no

18 os

19 mais

20 se

21 na

22 brasil

23 as

24 porque

25 tem
Freqüência

77141

67386

55749

52865

50298

32634

27687

26246

23472

21773

19764

18397

16991

16704

16252

15682

13648

12916

12126

11788

11402

10273

9753

9108

7839
Palavra

gente

pais

por

fazer

vocês

presidente

mas

como

muito

35 ao

36 aqui

37 isso

38 dos

39 이

40 ser

41 mel

42 val

43 governo

44 das

45 ter

46 está

47 nosso

48 já

49 república

50 quando
Freqüência

7734

7471

7222

6976

6799

6701

6414

6309

6170

6064

6020

5909

5866

5122

4879

4814

4754

4565

4541

4405

4402

4343

4324

4189

4145

BERBER-SARDINHA - Lula e a metáfora... 
Recebido em 18/05/07. Aprovado em 14/12/07.

\begin{abstract}
Title: Lula and the conquest metaphor
Author: Tony Berber Sardinha

Abstract: The aim of this study is to identify recurrent metaphors in the official speeches of the president of Brazil, Luís Inácio Lula da Silva. The corpus was made up of 868 talks, amounting to nearly 1.8 million words. With the help of Corpus Linguistics tools and a theoretical background centering around conceptual metaphor, we noted that the word 'conquista' ('conquest') stood out from among the other words with high metaphoric potential. The analysis of how this word was used showed that it is highly productive, generating a wide range of metaphors by combining with a large number of topics. This indicated that the 'conquest' is a key metaphor in the President's rhetorical arsenal, despite being little noted. In addition, the set of metaphors relative to 'conquest' is coherent with the President's life and ideology, which lends credibility to his discourse.
\end{abstract}

Keywords: metaphor; Corpus Linguistics; politics; discourse.

Titre: Lula et la métaphore de la conquête

Auteur: Tony Berber Sardinha

Résumé: L'objectif de ce travail est celui d'identifier et analyser les métaphores récurrentes dans les discours du Président Luís Inácio Lula da Silva. Le corpus employé dans la recherche est composé par 868 allocutions du président, comprenant presque 1,8 million de mots. Avec l'emploi d'outils de la Linguistique de Corpus et de la charpente théorique de la métaphore conceptuelle, on a remarqué que le mot 'conquête' se détachait parmi ceux de potentialité métaphorique dans le corpus. L'analyse de l'emploi de ce mot a démontré qu'il est trop productif, engendrant une grande variété de métaphores quand il s'accorde avec un nombre assez large de sujets. Cela veut dire que la conquête est une métaphore clé dans l'arsenal rhétorique du président, cependant peu remarqué. En outre, l'ensemble de métaphores relatives à la conquête est cohérente avec l'histoire de vie et l'idéologie politique du président, ce qui accorde crédibilité à son discours.

Mots-clés: métaphore; Linguistique de Corpus; politique; discours.

Título: Lula y la metáfora de la conquista

Autor: Tony Berber Sardinha

Resumen: El objetivo de este trabajo es identificar y analizar las metáforas recurrentes en los discursos y pronunciamientos del presidente Luís Inácio Lula da Silva. El corpus utilizado en la investigación está compuesto por 868 trechos de discurso del presidente, comprendiendo casi 1,8 millón de palabras. Con el uso de herramientas de la Lingǘstica de Corpus y de la estructura teórica de la metáfora conceptual, notamos que la palabra 'conquista' se destacaba entre las de potencial metafórico en el corpus. El análisis del uso de esa palabra mostró que ella es altamente productiva, generando una gran variedad de metáforas al combinarlas con un número alto de tópicos. Eso indica 
que la conquista es una metáfora clave en el arsenal retórico del presidente, aunque poco notada. Además de eso, el conjunto de metáforas relativas a la conquista es coherente con la historia de vida y la ideología política del presidente, lo que confiere credibilidad a su discurso.

Palabras-clave: metáfora; Lingüística de Corpus; política; discurso. 